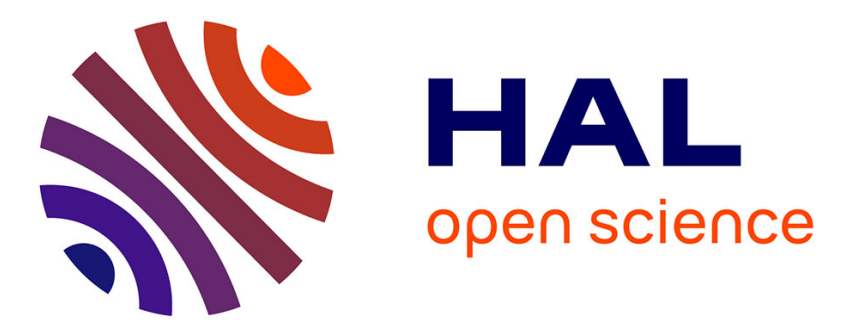

\title{
Monkey and dung beetle activities influence soil seed bank structure
}

\author{
François Feer, Jean-François Ponge, Sylvie Jouard, Doris Gomez
}

\section{To cite this version:}

François Feer, Jean-François Ponge, Sylvie Jouard, Doris Gomez. Monkey and dung beetle activities influence soil seed bank structure. Ecological Research, 2013, 28 (10), pp.93-102. 10.1007/s11284012-1006-9 . hal-00781281

\section{HAL Id: hal-00781281 \\ https://hal.science/hal-00781281}

Submitted on 25 Jan 2013

HAL is a multi-disciplinary open access archive for the deposit and dissemination of scientific research documents, whether they are published or not. The documents may come from teaching and research institutions in France or abroad, or from public or private research centers.
L'archive ouverte pluridisciplinaire HAL, est destinée au dépôt et à la diffusion de documents scientifiques de niveau recherche, publiés ou non, émanant des établissements d'enseignement et de recherche français ou étrangers, des laboratoires publics ou privés. 
$1 \quad$ Monkey and dung beetle activities influence soil seed bank structure

2

3

4 François Feer $^{1 \mathrm{a}}$, Jean-François Ponge ${ }^{\mathrm{a}}$, Sylvie Jouard ${ }^{\mathrm{a}}$ and Doris Gomez ${ }^{\mathrm{b}}$

5

6 a Muséum National d'Histoire Naturelle, CNRS UMR 7179, 4 avenue du Petit-Château, 791800 Brunoy, France

$8{ }^{\mathrm{b}}$ Centre for Evolutionary and Functional Ecology, CNRS UMR 5175, 1919 Route de Mende, 934293 Montpellier Cedex 5, France

10

$11{ }^{1}$ Corresponding author ; e-mail : feer@mnhn.fr

12

13

14

15

16

17

18

19

20

21 
1 Abstract

2 We investigated the influence of Neotropical dung beetles on soil seed bank structure after

3 primary dispersal by the red howler monkey (Alouatta seniculus). We collected seeds from

4 soil samples (up to $15 \mathrm{~cm}$ depth) in defecation versus control areas and showed that seed

5 number and diversity increased with monkey frequentation. Seed numbers decreased with

6 depth. Seed viability, ascertained from seed coat integrity, decreased with depth and was

7 higher in sites rarely visited by monkeys compared to control areas or sites frequently visited

8 by monkeys. In field experiments, we incorporated plastic beads $(1.3-5.8 \mathrm{~mm})$ to fresh dung

9 and monitored bead fate: the proportion of beads found in the soil top $10 \mathrm{~cm}$ increased with

10 bead size and this effect was more pronounced in sites more frequently visited by monkeys.

11 The same conclusions were drawn by comparing the beads found in the topsoil and the beads

12 found deeper. We explored bead processing behaviour in several tunneller and roller species

13 by performing experiments involving one species at a time. We showed that selectivity was

14 highly variable: bead exclusion from dung reserves was higher in small than in large beetle

15 species, higher for large than for small beads. Differences in selectivity between medium and

16 small beads decreased for greater per-capita resource, an effect which was more pronounced

17 with small species and with rollers. These results support a major role of dung beetles in soil

18 seed bank structure and dynamics. They reveal interesting interspecific variability within the

19 dung beetle community, a complex interplay with primary dispersal, and a possible role of

20 competition between dung beetles calling for more refined investigations.

22 Key words: French Guiana; Dung beetles; Pioneer species; Howler monkey; Soil seed bank. 


\section{INTRODUCTION}

2 The seed dispersal process commonly comprises two phases (diplochory), each involving a different dispersal agent. In tropical forests, frugivorous animals like monkeys can promote long distance escape away from the parent plant, thus acting as major seed primary dispersers. Secondary dispersers like dung beetles or other insects relocate the dung deposited by frugivorous mammals, dispersing seeds at short range, a process which can lower seed mortality by reducing aggregation or by placing seeds in favourable microsites for germination (Engel 2000, Wenny 2001, Vander Wall and Longland 2004). Soil seed bank structure and dynamics are influenced both by primary and secondary dispersers (Dalling 2005). Dung produced by frugivorous animals often contains large quantities of small seeds, many of which are from pioneer plant species in the Neotropical region. Hence, diplochory appears as one of the major biotic processes involved in the early regeneration of tropical forests.

Red howler monkeys act as important primary dispersers. They promote local concentration of small seeds through their highly variable site-specific defecation behaviour, this variability being possibly due to the occurrence of monkey visits, but also to a differential in the activity of secondary dispersers (Julliot et al. 2001, Pouvelle et al. 2009). Dung beetles are ubiquitous in tropical forests and play an important role in seed secondary dispersal. According to their food relocation behaviour they either bury seeds directly below dung deposits as tunnellers or dwellers, or move them away in dung balls as rollers (Andresen and Feer 2005). Experiments with Neotropical dung beetles have shown that smaller seeds are buried in greater amount and at greater depth than larger seeds (review in Andresen and Feer 2005). Dwellers bury seeds just below the soil surface (Vulinec 2002). Tunnellers bury seeds in larger proportion than rollers, the latter group being never observed to bury seeds larger than $5 \mathrm{~mm}$ in length (Vulinec 2002). Finally, larger beetles bury seeds at greater depth than smaller beetles (Vulinec 2000). Burial protects seeds from terrestrial predators like rodents and places seeds in safe and fertile sites for seedling establishment (Andresen and Levey 2004, Dos Santos Neves et al. 2010). It has recently been demonstrated that dung beetles reduce the spatial aggregation of tropical seedling which may enhance their survival (Lawson et al 2012). Dung beetles have been shown to be highly active as they are able to process dung and its content in a few hours (Feer 1999). Because of their rapidity and abundance, dung beetles are likely highly effective agents of secondary dispersal.

In the present study, we set out to investigate the origins of soil seed bank variability in relation to monkey and dung beetle activity. Identifying the factors responsible for such a 
1 variability is crucial to assess its impact on seed fate (mortality, competition for germination and recruitment), and ultimately on forest dynamics. Focusing on the system primate-beetle is interesting to assess the potential adaptability of beetles to resource availability. Understanding this system is particularly timely in the current context of threat on biodiversity, particularly on primates.

Possible and mutually non-exclusive causes for seed accumulation may be recurrent monkey frequentation (Muñoz Lazo et al. 2011), modifications (saturation or increase) of dung beetle activity, greater activity of tunnellers or dwellers compared to rollers (tunnellers being less efficient in dispersing seeds away from dung deposits), and strong selectivity in seed exclusion from dung reserves (Feer 1999).

First, we question whether increased monkey frequentation translates into differences in the structure of soil seed bank. Potential differences may result from differences in activity of monkeys, dung beetles, or other dispersers or consumers. If such differences have already been observed in previous studies (Pouvelle et al. 2009), it is crucial to examine the existence of potential differences in this study before testing the implication of dung beetles. We analysed soil seed bank structure - number of seeds, species richness, seed viability at various depths - in sites differing by monkey frequentation.

Second, we question whether dung beetles are similarly effective at all sites or more active in sites more often frequented by monkeys. Differences in activity may result from differences in beetle assemblages (in number of species, species identity, and/or number of individuals) or from an increased activity shown by all individuals (due to a higher temperature or a higher stimulation triggered by cues delivered by dung or seeds for instance). It is crucial to examine the existence of potential differences in activity before questioning some of their possible origins. Hence, in a field experiment using artificial beads, we tracked beads translocated by dweller or tunneller species to estimate the relative topsoil activity of these functional groups in sites differing by monkey frequentation.

Third, we question whether dung beetle activity (quantity of dung processed) and selectivity (seed exclusion from processed dung - efficiency of seed dispersal according to seed size) varies with beetle dung relocating behaviour (tunneller versus roller), beetle size and dung availability (per capita resource). We chose the most abundant or specialised species and conducted experiments in which we placed a variable number of individuals of the same species in containers provided with dung and artificial beads. The analysis of dung processing and bead dispersal allowed us to estimate beetle activity and potential effects of intraspecific competition on seed dispersion patterns. 
METHODS

3

\section{1) Study site and species}

This study was conducted at the Nouragues Research Station (French Guiana), located 100 $\mathrm{km}$ south of Cayenne $\left(4^{\circ} 5^{\prime} \mathrm{N}, 52^{\circ} 41^{\prime} \mathrm{W}\right.$, alt. $110 \mathrm{~m}$ a.s.1.) in a $1000 \mathrm{~km}^{2}$ wilderness reserve dominated by tropical rain forest (Charles-Dominique 2001). The average annual rainfall is $2990 \mathrm{~mm}$ and the mean temperature is $26.3{ }^{\circ} \mathrm{C}$ (Grimaldi and Riéra 2001). The dominant vegetation type is a high mature forest with canopy at 30-35 m (Poncy et al. 2001). The howler monkey (Alouatta seniculus L.) is the dominant primate in the study area, feeding on ripe, fleshy fruits and foliage (Julliot and Sabatier 1993, Simmen et al. 2001). Among the 97 plant species which constitute its diet, fruits of 21 species have seeds of $\leq 0.1 \mathrm{~g}$, of which 10 make 21.6 percent of the monkey diet (Julliot 1994). Monkeys rest or sleep in particular tree crowns, some of them regularly or seasonally used for several years, while others are used more erratically (Julliot 1996a). They generally defecate after resting, scattering their dung on the ground over about $10 \mathrm{~m}^{2}$, enriching the soil microsite with seeds which accumulate over the course of time (Julliot et al. 2001). The majority of seeds remain viable once they have transited through howler guts (Julliot 1996b, Pouvelle et al. 2009). Besides seed concentration, the input of dung enriches soil nutrients particularly in the areas where defecation occurs more frequently (Feeley 2005, Dos Santos Neves et al. 2010).

The local dung beetle community shows a high species diversity (79 species attracted to howler monkey dung; Feer 2000, F. Feer unpubl. data). Species are specialized according to diet, diel activity rhythm and dung-processing behaviour (see species checklist and ecological characteristics in Feer and Pincebourde 2005).

\section{2) Effect of monkey frequentation on soil seed bank structure - soil sampling}

To explore the impact of monkey defecation activity on seed secondary dispersal by the dung beetle community, we sampled the soil seed bank in October and November 2007 at eight sleeping sites visited by howler monkeys. Sites were scattered around a 13 ha area and were at least $30 \mathrm{~m}$ apart. Based on tree cartography and field inspection, we checked that there was no treefall gap, no Cecropia or Ficus spp. adult tree within $50 \mathrm{~m}$ of site and control areas. This ensured that (1) there was no direct influence of gaps on the study sites and (2) the presence in the soil seed bank of small seeds from dominant plant species was essentially due 
to dispersal. Sites were categorised in two groups according to the number of monkey visits we were able to observe during the months of October-November in 2006 and in 2007:

- Sleeping sites rarely frequented by monkeys (freq-, $N=6$ ) received one or two visits in two years (one or none in 2006 and one visit in 2007);

- Sleeping sites often frequented by monkeys (freq+, $N=2$ ) received at least four visits in two years (at least two in 2006 and two visits in 2007). The maximal number of visits observed was seven.

Control areas were never visited by monkeys (control) in 2006 and 2007. A control area was arbitrarily defined $15 \mathrm{~m}$ east of a sleeping site, thereby outside the defecation area but in similar vegetation and soil conditions. In statistical analyses, a control area and its associated defecation area were considered as belonging to the same "site".

We defined sampling areas in the morning shortly after a defecation event was spotted. We first determined the centre of the defecation/control area which we used as the centre of a $2 \times 2 \mathrm{~m}$ square. We labelled 9 sampling points for each area: the centre of the area, as well as 8 points along the perimeter of the square, $1 \mathrm{~m}$ apart from one another. We took topsoil samples from the 9 sampling points within each area 48 hours after defecation events when all dung seemed to have been processed by dung beetles. At each sampling point, six successive layers were dug with a 5 -cm-diameter drill: the first 5 layers were $2 \mathrm{~cm}$ thick while the last one was $5 \mathrm{~cm}$ thick. Digging deeper than $15 \mathrm{~cm}$ was uneasy because of the presence of numerous tree roots and deeper burial depths are considered much less effective in terms of regeneration potential (Dalling et al. 1994). Soil samples of the same depth layer were pooled over the 9 sampling points, transferred to plastic bags and sieved at $0.1 \mathrm{~mm}$ under tap water later on during the same day. Seeds, intact or not, were rapidly sorted and sealed in black plastic bags to avoid light-favoured (photoblastic) germination. Once back at the laboratory, plant species were identified at the species level whenever possible, using the laboratory seed collection from French Guiana and species lists for the Guianan rain forest established by Favrichon (1994). Seeds were kept in a fresh state, and thoroughly inspected with forceps under a dissecting microscope. Coat inspection was used to score seed viability (Borza et al. 2007): viable (intact and firm coat) or non viable (void, tunnelled or damaged coat).

\section{3) Dung beetle activity at sites differing in monkey frequentation - field experiments with beads}

Fresh monkey dung was used for experiments set out in 10 defecation areas: the 8 previously selected and two newly discovered areas both from freq+ category (4 freq+ sites and 6 freq- 
1 sites). Preliminary experiments conducted in five sampling areas showed that when an enclosure prevented dung beetles from processing dung during $48 \mathrm{~h}$, dung went mouldy without any change in structure and without any sign of activity from other agents. As a consequence, we did not perform control experiments with enclosures systematically in association with each defecation area. Round plastic beads were used as seed mimics (e.g. Andresen 2002). Seed artefacts were preferred to real seeds to prevent confusion with seeds naturally present in dung. We used a mixture of beads of three different diameters: small (1.3$1.9 \mathrm{~mm} ; N=200$ per replicate), medium $(3.3-3.7 \mathrm{~mm} ; N=80)$ and large $(4.8-5.8 \mathrm{~mm} ; N=$ 10). On the day monkeys defecated in a specific area, we placed $80 \mathrm{~g}$ of fresh dung with embedded beads randomly on the ground within the defecation area but outside the area for soil sampling. We placed these pseudo-defecations between 7.00 and 9.30 AM, shortly after the monkey visit, to mimic exact conditions of site use by these primates. We estimated the proportion of dung buried or removed 12 and 24 hours after the beginning of the experiment. Soil samples were taken $48 \mathrm{~h}$ after dung deposition. At each sampling point we sampled soil layers at 1, 2, 468 and $10 \mathrm{~cm}$ depth within a $23 \mathrm{~cm}$ diameter circular area. Beads were counted by sieving soil samples to calculate the proportion of beads buried by beetles at the different depths. Only few beads were visible on the soil surface. We considered that beads in the 0-1 cm layer were processed mostly by dwellers (Vulinec 2000, F. Feer personal observation) whereas the remaining beads were processed by tunnellers. Missing beads were buried deeper than $10 \mathrm{~cm}$ or moved by rollers away from the area surveyed.

\section{4) Relative activity and selectivity of the most abundant beetle species - container experiment with artificial beads}

We selected six dung beetle species among those most frequently captured in pitfall traps baited with howler monkey dung (see Feer 2000) and/or most frequently observed in howler monkey defecation areas or perching on leaves nearby (Feer, pers. obs. since 1995). As beetle activity with respect to dung increases with beetle size (Vulinec 2000), we disregarded some species that were more abundant but smaller, retaining only species longer than $7 \mathrm{~mm}$. We thus selected the three rollers Hansreia affinis (9.2 mm length), Canthon bicolor (10.2 $\mathrm{mm})$ and Glaphyrocanthon vulcanoae $(12.6 \mathrm{~mm})$ and the three tunnellers Canthidium cf onitoides (7.3 mm), Oxysternon durantoni $(16.4 \mathrm{~mm})$ and Dichotomius boreus $(23.7 \mathrm{~mm})$ (see species ecological characteristics in Feer and Pincebourde 2005).

To test for interspecific variability in dung processing and potential differences in selectivity (active exclusion of beads from processed dung resource), we performed a series of 
1 experiments (from 2 to 4 per species) on each species separately. We placed 2 to 7 individuals

2 in a mesh-covered 30 -cm-diameter cylindrical container filled with soil $(20 \mathrm{~cm}$ deep for 3 tunnellers; $10 \mathrm{~cm}$ deep for rollers) and with fresh dung with plastic beads (40-50 g dung with 4100 small, 40 medium and 5 large beads for tunnellers; $30 \mathrm{~g}$ dung with 50 small, 30 medium and 5 large beads for rollers). Containers were left aside for $72 \mathrm{~h}$. They were subsequently excavated centimeter by centimeter for buried beads and dung balls were examined for incorporated beads. Rollers were disturbed by the small size of the containers and did not bury all of the balls. We estimated the proportion of processed dung by weighing dung reserves and remaining dung.

\section{5) Statistical analysis}

Data were analysed using generalized linear mixed models. Such models are widely recommended in ecology as they provide a flexible and robust approach for analysing nonnormal data when random effects are present (Bolker et al. 2009). Depending on which variable we tested, we took a Poisson or a binomial structure for the dependent variable. With mixed models, it is possible to separate fixed effects from random effects. Fixed effects are biologically relevant predictor variables which permit to extract a general "principle". For instance, we tested depth as a fixed factor to examine the vertical structure of seed soil bank and the general rule of how seeds (numbers, richness, viability) varied with depth.

Conversely, random effects are designed to capture the undesirable variability intrinsic to protocol design but of no particular general value. For instance, we repeatedly sampled the same site or container at different depths. Site (or container) had to be taken as a random effect to account for these repeated observations, and for the natural variability among sites which was not interesting as a rule (sites had no value in themselves as they would change if we were to conduct the experiment again). For container experiments, the experiment (that is the container itself) was taken as the random effect. For soil samples and field experiments with plastic beads, we tested either site (mean value varying randomly among sites) or depth within site (mean value and relationship with depth varying randomly among sites) as a random effect. As explained in detail by Bolker et al (2009), taking a given factor as a random effect and a fixed factor allowed to part its variability into undesired (due to variations of soil between sites, the variation of seeds with depth may vary randomly between sites) and relevant variation (general effect common to all sites).

Concerning soil sampling, the variable to explain was seed number, species richness and seed viability (proportion of viable seeds). As fixed effects, we tested the interactions 
1 between seed depth (taken as mean layer depth, analysed in logarithm), and the monkey

2 frequentation effect (three levels: control, freq- and freq+). For the latter effect, we built two 3 independent contrasts: the first tested the difference between control and monkey sites 4 (control < [freq-, freq+]); the second tested monkey frequentation (freq- $<$ freq + ). We weighted species richness by the number of seeds found in the soil layer to correct for biases due to seed abundance.

Concerning the field experiment with beads, we analysed the proportion of beads found at different depths. First, we included all five $2 \mathrm{~cm}$ thick layers to explore bead vertical distribution. Second, we contrasted the first centimetre $(0-1 \mathrm{~cm})$ and the rest of the soil column $(1-10 \mathrm{~cm})$ to gain insights about seed vulnerability to predation or infection. Despite being processed by dwellers, seeds near the soil surface remain more vulnerable to predation than deep-buried seeds (Andresen and Levey, 2004). As fixed effects, we tested the interactions between bead depth (taken as mean layer depth, analysed in logarithm), monkey frequentation effect (two levels: freq- and freq+) and bead size (small, medium and large with two contrasts: $\mathrm{M}<\mathrm{S}$ and $\mathrm{L}<[\mathrm{M}, \mathrm{S}])$.

Concerning the experiment with containers, we first analysed the ratio of the proportion of beads in the processed dung to the proportion of beads in the dung delivered. Decreasing values corresponded to increasing selectivity (exclusion of beads from the processed dung). Second, we analysed the depth at which beads were buried. As fixed effects, we tested the interactions between functional group (roller or tunneller), species body size (length in $\mathrm{mm}$ ), proportion of dung processed, per-capita resource (computed as the ratio of dung delivered to the number of individuals), and bead size (small, medium and large with two contrasts $(\mathrm{M}<\mathrm{S}$ and $\mathrm{L}<[\mathrm{M}, \mathrm{S}])$. We only tested one to three-way interactions as more complex models could not yield any sound biological interpretation.

We used a maximum likelihood approach and minimization of Akaike's Information Criteria (AIC) to select the best statistical models according to the parsimony principle, considering that two models differing by less than two AIC units are statistically indistinguishable, as currently accepted (Burnham and Anderson 1998). We corrected AIC values for potential residual overdispersion and small differences between the number of parameters estimated and the number of observations (Bolker et al. 2009). We first selected the random effect via AIC minimization based on the full model, as suggested by Bolker et al. (2009). Once the random effect was selected, we selected fixed effects using the same method. Coefficients and standard errors were computed using a restricted maximum likelihood approach and factor significance was tested using Wald z tests (Bolker et al. 2009). 
1 All statistics were performed using $\mathrm{R}$ version 2.11.1 (copyright 2008, The R Development 2 Core Team).

3

4

5

\section{RESULTS}

\section{1) Influence of monkey frequentation on soil seed bank structure}

Soil samples contained a total of 1922 seeds from 72 plant species (Online Table 1). Monkey frequentation affected seed numbers, species richness, and seed viability. These variables exponentially decreased with depth. Seed number and species richness increased with monkey frequentation (control < freq- < freq+, Table 1, Figure 1). Compared to control sites, sites visited by monkeys had a smoother decrease in seed number and species richness with depth. Yet, the decrease in seed number - but not in species richness - was marginally steeper in sites often visited by monkeys compared to sites rarely visited (more seeds in top layers and less in deeper layers).

We observed that seeds buried deeper had a lower viability. Seed viability decreased exponentially when depth increased. Seed viability was similar in control areas and in sites often visited by monkeys (control $<$ freq,$+ P=0.83$ ) while it was lower than in sites rarely visited by monkeys (Table 1, Figure 1, [control, freq+]<freq-, $P<0.001$ ), suggesting that monkey activity could have positive or negative effects on seed viability depending on its intensity.

\section{2) Influence of monkey frequentation on dweller and tunneller activity}

Between $50 \%$ and $95 \%$ of dung was buried 12 hours after deposition, and $100 \%$ disappeared after $24 \mathrm{~h}$. A total of $59 \%$ of beads (total $N=2,900$ ) were found in the top $10 \mathrm{~cm}$ in the area surveyed around dung deposits and resulted from tunneller and dweller burying activity. The remaining $41 \%$ were either buried more deeply by tunnellers or translocated away by rollers. In the top $10 \mathrm{~cm}$ of soil, the proportion of buried bead varied with bead size, depth (five levels) and monkey site frequentation. This proportion increased with bead size (bead size effect, $P<0.001$, online Table 2). It exponentially decreased when depth increased (depth effect, $P<0.001$ ), a variation that was more pronounced for larger beads (depth $\mathrm{x}$ bead size effect, $P<0.01)$. The difference in proportion between small and medium beads was more pronounced in sites often visited by monkeys (frequentation x bead size effect, $P<0.001$ ), and this effect faded with depth (frequentation $\mathrm{x}$ depth $\mathrm{x}$ bead size effect, $P<0.001$ ). 
Comparing the proportion of beads buried superficially by dwellers and to that buried by tunnellers yielded similar results. We found a higher proportion of beads near the surface than deeper in the soil (more than $50 \%$ of beads found; $P<0.001$ ) and this difference increased with bead size $(P<0.001)$. The difference between small and medium beads was more pronounced in sites more often visited by monkeys $(P<0.001)$. The lack of interaction between depth and frequentation suggested that dwellers and tunnellers were similarly affected by site frequentation by monkeys.

(1)

\section{3) Relative activity and selectivity of most abundant beetle species}

Beetle selectivity for seed size (inversely related to proportion of bead retrieved) depended on all possible triple interactions between beetle size, bead size, functional group and proportion of resource available per capita. For a given body size, rollers and tunnellers did not show any difference in how selective they were when in the presence of seed artefacts (beads). Beetles were less selective for small than medium beads (bead size effect, $P<0.001$, online Table 2), and for large than (small and medium) beads (bead size effect, $P<0.01$ ). Difference in selectivity between large and smaller beads decreased in larger beetles (beetle size $\mathrm{x}$ bead size effect, $P<0.001$, Fig. 2), an effect which faded for greater per-capita resource (beetle size $\mathrm{x}$ bead size $\mathrm{x}$ part, $P<0.001$ ). Difference in selectivity between medium and small beads decreased for greater per-capita resource (bead size x part effect, $P<0.001$, Fig. 3), an effect which faded in larger beetles (bead size $\mathrm{x}$ part $\mathrm{x}$ beetle size effect, $P<0.001$ ). Variation in selectivity between medium and small beads faded with increasing per-capita resource, more strongly in tunnellers than in rollers (bead size x part x mode effect, $P<0.001$ ). Finally, selectivity between medium and small beads faded with increasing beetle size, more strongly in tunnellers than in rollers (bead size $\mathrm{x}$ mode $\mathrm{x}$ beetle size, $P<0.001$ ).

Between 21.2 percent $(N=33$ balls, $H$. affinis $)$ and 33.3 percent $(N=9$ and $N=15$ for $G$. vulcanoae and $C$. bicolor, respectively) of dung balls made by roller species contained beads. A higher proportion of balls contained natural seeds $(91.2 \%, N=57)$, which were smaller in size than small beads (Ficus spp.) or than medium beads (Cecropia obtusa, C. sciadophylla). The largest seed species found in balls was Bagassa guianensis (4.0 mm).

The depth at which tunnellers buried beads varied with bead size and beetle size. Smaller beads were buried at greater depths (bead size effect, $P<0.001$, online Table 4). Larger beetles buried beads at greater depths $(P<0.001)$. The difference in burial depth between large beads and smaller beads decreased as beetle size increased $(P<0.001)$. The 
1 largest species $D$. boreus was the less selective, burying all beads at high depth levels (total 2 average: $13.6 \pm$ CI $0.6 \mathrm{~cm}$ ), with maximum depth reaching the bottom of the container,

3 whereas the smaller $O$. durantoni buried large beads less deeply than other beads $(13.4 \pm \mathrm{CI}$ $4 \quad 0.8 \mathrm{~cm})$. The smallest species $C$. onitoides $(4.3 \pm$ CI $1.2 \mathrm{~cm})$ did not bury large beads and buried medium beads at lower depth levels than small beads.

\section{DISCUSSION}

\section{Impact of monkey frequentation}

We confirm that endozoochory by the red howler monkey can result in high local concentrations of small seeds. Small seeds are significantly more abundant and diverse in defecation areas than in control areas, a result that agrees with previous studies (Julliot 1992, Pouvelle et al. 2009). More interestingly, we first show that site frequentation by monkeys increases seed accumulation. Such an accumulation unlikely results from a saturation of activity by dung beetle assemblages as all deposited dung was processed quickly at all sites; if it were the case, we would have found a much pronounced accumulation of seeds at the soil surface, a situation that has been observed in forests where beetle fauna is impoverished (Larsen et al. 2005).

Monkey frequentation has negative effects on seed viability: seed viability is higher at sites rarely used by monkeys compared to control areas or sites frequently used by monkeys. Given that seed viability slowly decreases with time, frequent dung inputs should induce an increase in the proportion of viable seeds. Yet, reduced viability suggests negative effects of high seed density and/or high local concentrations of dung. Such negative effects may be caused by fungal infection, which occurs despite protective structures which enhance seed longevity in the soil seed bank (Lobova et al. 2003). Fungal infection decreases seed survival for Cecropia spp. (Dalling et al. 1998) and is more pronounced for Ficus maxima seeds embedded in howler monkey faeces than for seeds outside (Jones 1994). Seed viability decreases with depth, as shown in a previous study (Pouvelle et al. 2009), probably due to the lesser renewal rate of seeds in deeper soil layers. By contrast, Dalling et al. (1998) showed that deeply buried seeds survive longer than seeds located near soil surface, likely because of a lower pathogen activity at greater depths. Yet, their experiments were conducted in the absence of dung and do not tell anything about the possible influence of gut and dung components on seed fate. 


\section{$1 \quad$ Rapid and monkey-dependent activity of dung beetles}

2 Our field experiments with beads confirm that dung beetles rapidly process large amounts of dung (within 24h, see also Feer 1999). As this effect is not observed when dung beetles are excluded, we can conclude that they are the dominant agent affecting small seed fate after primary dispersal. Other agents likely play a minor role in small seed processing. Rainfall may bury small seeds but only at shallow depths ca $1 \mathrm{~cm}$ and slowly in a few weeks time (Marthews et al. 2008). Earthworms active in latrines (Pouvelle et al. 2008, Dos Santos Neves et al. 2010) are known to ingest and move small seeds in tropical grasslands (Decaëns et al. 2003). Although their contribution to seed movements is unknown in rainforests, it should be slow compared to burial by beetles. Litter ants, known to process small seeds from bird and primate dung (Pizo et al. 2005), likely process only small amounts of dung.

Small beads are moved or buried more often and more deeply than large beads, in accordance with previous observations on seeds (Estrada and Coates-Estrada 1991, Sheperd and Chapman 1998, Andresen 1999, 2002). Hence, dung beetles are key contributors to the presence of small seeds of pioneer monkey-dispersed tree species in deep soil strata. The experiment with beads reveals that differences in retrieval and burial rates between small and medium beads are more pronounced in the most often visited areas, the first evidence of an influence of monkey frequentation on beetle activity. This pattern may emerge from different non-exclusive processes: (1) regular dung deposition may produce more attractive components to roaming beetles, (2) beetles may more actively explore areas more often frequented by monkeys, (3) beetle assemblages may be spatially structured, with higher densities and functional diversity in areas with more frequent (and thus predictable) resource availability. These results call for more research concerning beetle population structuring, behaviour and activity patterns. Flying dung beetles have been seen following monkey troops (Vulinec and Quintero cited in Tirado Herrera et al. 2002), a strategy that fosters more efficient food location for these highly specialised animals. Yet, no study has explored the existence of vertebrate-dependent spatial organisation in beetle populations.

\section{Dung beetle selectivity in seed processing}

Dung beetles show a significant selectivity in their processing of artificial seeds, more actively rejecting larger-sized beads. Selectivity depends on beetle body size, smaller species being more selective than larger species, a result which confirms previous studies (Estrada and Coates-Estrada 1991, Andresen 1999, Feer 1999). In French Guiana rainforest, rollers are 
1 body size, tunnellers and rollers do not show any difference in selectivity, we suggest that, as

2 a whole, rollers are likely more selective than tunnellers. A higher selectivity by rollers has been detected experimentally (Vulinec 2002, Slade et al. 2007), likely in relation with a relatively small (dung ball mass: beetle size) ratio (Hanski and Cambefort 1991, F. Feer unpublished data). As selectivity depends on body size, we predict that large tunnellers bury a larger number of seeds at higher depths than small tunnellers. The potential for emergence of light-demanding tree species with photoblastic germination, such as Cecropia spp., is limited to the upper layer of the soil (Pearson et al. 2003). Hence, we can speculate that large tunnellers put seeds of those species in less favourable conditions for germination than all other dung beetles. By contrast, dung processed by dwellers is very unlikely processed by other beetles. Hence, by maintaining seeds near the soil surface, dwellers put them in favourable conditions for further germination.

We show for the first time that selectivity increases when resources available per individual decrease, suggesting that beetles perceive the level of potential intraspecific competition (as estimated by the per capita resource) and adapt their behaviour accordingly. In a context of more intense intra-specific competition, individuals avoid incorporating unpalatable items into their dung reserve, a behaviour that improves dung nutritional value. Whatever their dung processing behaviour (roller or tunneller), smaller species show more pronounced changes in their seed exclusion behaviour. For a given body size and a given decrease in per-capita resource, rollers get more selective than tunnellers and exclusion concerns a larger range of seed sizes. Altogether, our results suggest that rollers likely entail higher costs than tunnellers in carrying non-palatable items in their dung balls, either because of carrying energetic costs or fitness consequences for offspring. Surprisingly, intense competition does not lead to hastened dung processing but to more careful dung processing, with more active exclusion of unpalatable seeds, a behaviour which likely improves the quality of dung balls at the expense of time saving. We can speculate that in a context of high competition, adults may favour the quality of food provisioning to offspring at the expense of offspring number (number of balls produced). To date, several studies suggest that exploitative and interference competition is quite intense in tropical dung beetle communities (Peck and Forsyth 1982, Gill 1991) which differ from temperate communities (Finn and Gittings 2003). Experimental studies demonstrate that some species have the potential for fierce interspecific competition for food (Giller and Doube 1989, review in Hanski and

33 Cambefort 1991). Specific tests are required to assess the importance and modalities of intra and interspecific competition in tropical rainforest dung beetle communities. 
As a conclusion, dung beetles appear able to adapt their activity to resource temporal and spatial availability (sensitivity to monkey activity, to intraspecific competition). The exact and complex mechanisms leading to this flexibility remain to be studied. Yet, we can predict that any limitation of primate density induced by forest fragmentation or hunting is expected to impact beetle community, to disturb the diplochory process and thereby the dynamics of small-seeded tree species.

\section{ACKNOWLEDGMENTS}

We are indebted to the staff of the Nouragues Research Station (CNRS, French Guiana), for commodities and technical help during the field session. We thank P.-Y. Henry for useful comments on data analysis and the anonymous reviewers for comments on the manuscript. Financial support was provided by the National Museum of Natural History (Paris, France) and the CNRS (UMR 7179).

\section{LITERATURE CITED}

Andresen E (1999) Seed dispersal by monkeys and the fate of dispersed seeds in a Peruvian rainforest. Biotropica 31: 145-158

Andresen E. 2002. Dung beetles in a Central Amazonian rainforest and their ecological role

Andresen E, Levey D J (2004) Effects of dung and seed size on secondary dispersal, seed predation, and seedling establishment of rain forest trees. Oecologia 139: 45-54

Andresen E, Feer F (2005) The role of dung beetles as secondary seed dispersers and their

Bolker B M, Brooks M E, Clark C J, Geange S W, Poulsen J R, Stevens M H H, White J-S S (2009) Generalized linear mixed models: a practical guide for ecology and evolution. 
Borza JK, Westerman PR, Liebman M (2007) Comparing estimates of seed viability in three foxtail (Setaria) species using the imbibed seed crush test with and without additional tetrazolium testing. Weed Technology 21: 518-522

Burnham K P, Anderson D R (1998) Model selection and inference. A practical information theoretic approach. Springer-Verlag, New York

Charles-Dominique P (2001) The field station. In: Bongers F, Charles-Dominique P, Forget P-M , Théry M (eds) Nouragues: dynamics and plant-animal interactions in a neotropical rainforest. Kluwer, Dordrecht, The Netherlands, pp 1-7

Culot L, Mann DJ, Muñoz Lazo FJJ, Huynen M-C, Heymann EW (2011) Tamarins and dung beetles: an efficient diplochorous dispersal system in the Peruvian Amazonia. Biotropica 43: 84-92

Dalling, J W (2005) The fate of seed banks: factors influencing seed survival for lightdemanding species in moist tropical forests. In Forget P-M, Lambert J E, Hulme P E, Vander Wall S B (eds) Seed fate: predation, dispersal and seedling establishment. CABI, Wallingford, UK, pp 31-44

Dalling, J W, Swaine M D, Garwood N C (1994) Effect of soil depth on seedling emergence in tropical soil seed-bank investigations. Funct Ecol 9: 119-121

Dalling, J W, Swaine M D, Garwood N C (1998) Dispersal patterns and seed bank dynamics of pioneer trees in moist tropical forest. Ecology 79:564-578

Decaëns T, Mariani L, Betancourt N, Jimenez J J (2003) Seed dispersion by surface casting activities of earthworms in Colombian grasslands. Acta Oecol 24: 175-185

Dos Santos Neves N, Feer F, Salmon S, Chateil C, Ponge J-F (2010) The impact of red howler monkey latrines on the distribution of main nutrients and on topsoil profiles in a tropical rain forest. Aust Ecol 35: 549-559

Engel T R (2000) Seed dispersal and forest regeneration in a tropical lowland biocenosis (Shimba Hills, Kenya). Logos Verlag, Berlin, Germany.

Estrada A, Coates-Estrada R (1991) Howler monkeys (Alouatta palliatta), dung beetles (Scarabaeidae) and seed dispersal: ecological interactions in the tropical rain forest of Los Tuxtlas, Mexico. J Trop Ecol 7: 459-474 
Favrichon V (1994) Classification des espèces arborées en groupes fonctionnels en vue de la réalisation d'un modèle de dynamique des peuplements en forêt guyanaise. Rev Ecol 49: 379-403

Feeley K (2005) The role of clumped defecation in the spatial distribution of soil nutrients and the availability of nutrients for plant uptake. J Trop Ecol 21: 99-102

Feer F (1999) Effects of dung beetles (Scarabaeidae) on seeds dispersed by howler monkeys (Alouatta seniculus) in the French Guianan rain forest. J Trop Ecol 15: 1-14

Feer F (2000) Les Coléoptères coprophages et nécrophages (Scarabaeidae s. str. et Aphodiidae) de la forêt de Guyane française: composition spécifique et structure des peuplements. Ann Soc Entomol Fr. 36: 29-43

Feer F, Pincebourde S (2005) Diel flight activity and ecological segregation within an assemblage of tropical forest dung and carrion beetles. J Trop Ecol 21: 21-30

Finn JA, Gittings T (2003) A review of competition in north temperate dung beetle communities. Ecol Entomol 28: 1-13

Giller P S, Doube B M (1989) Experimental analysis of inter- and intraspecific competition in dung beetle communities. J Anim Ecol 58: 129-142

Grimaldi M, Riéra B (2001) Geography and climate. In: Bongers F, Charles-Dominique P, Forget P-M, Théry M (eds) Nouragues: dynamics and plant-animal interactions in a neotropical rainforest. Kluwer, Dordrecht, The Netherlands, pp 9-18

Hanski I, Cambefort Y (1991) Dung beetle ecology. Princeton University Press, Princeton. N.J.

Jones M B (1994) Secondary seed removal by ants, beetles, and rodents in a Neotropical moist forest. MSc Dissertation, University of Florida

Julliot C (1992) Utilisation des ressources alimentaires par le singe hurleur roux, Alouatta seniculus (Atelidae, Primates), en Guyane: impact de la dissémination des graines sur la régénération forestière. $\mathrm{PhD}$ Dissertation, University of Tours, France

Julliot C (1994) Frugivory and seed dispersal by red howler monkeys: evolutionary aspect. Rev Ecol 49: 331-341

Julliot C (1996a) Fruit choice by red howler monkeys (Alouatta seniculus) in a tropical rain forest. Am J Primat 40: 261-282 
Julliot C (1996b) Seed dispersal by red howler monkeys (Alouatta seniculus) in the tropical rain forest of French Guiana. Int J Primat 17: 239-257

Julliot C (1997) Impact of seed dispersal by red howler monkeys Alouatta seniculus on the seedling population in the understorey of tropical rain forest. J Ecol 85: 431-440

Julliot C, Simmen B, Zhang S (2001) Frugivory and seed dispersal by three neotropical primates: impact on plant regeneration. In: Bongers F, Charles-Dominique P, Forget PM, Théry M (eds) Nouragues: dynamics and plant-animal interactions in a neotropical rainforest. Kluwer, Dordrecht, The Netherlands , pp 197-205

Julliot C, Sabatier D (1993) Diet of the howler monkey (Alouatta seniculus) in French Guiana. Int J Primatol 14:527-550

Larsen T, Williams N M, Kremen C (2005) Extinction order and altered community structure rapidly disrupt ecosystem functioning. Ecol Lett 8: 538-547

Lawson CR, Mann DJ, Lewis OT (2012) Dung beetles reduce clustering of tropical tree seedlings. Biotropica 44: 271-275

Lobova T A, Mori S A, Blanchard F, Peckham H, Charles-Dominique P (2003) Cecropia as food resource for bats in French Guiana and the significance of fruit structure in seed dispersal and longevity. Am J Bot 90: 388-403

Marthews T R, Mullins C E, Dalling J W, Burslem F R P (2008) Burial and secondary dispersal of small seeds in a tropical forest. J Trop Ecol 24: 595-605

Muñoz Lazo FJJ, Culot L, Huynen M-C, Heymann EW (2011) Effect of resting patterns of tamarins (Saguinus fuscicollis and Saguinus mystax) on the spatial distribution of seeds and seedling recruitment. Int J Primatol 32: 223-237

Pearson T R H, Burslem F R P, Mullins C E, Dalling J W (2003) Germination ecology of neotropical pioneers: interacting effects of environmental conditions and seed size. Ecology 83: 2798-2807

Peck S B, Forsyth A (1982) Composition, structure and competitive behaviour in a guild of Ecuadorian rain forest dung beetles (Coleoptera: Scarabaeidae). Can J Zool 60: 16241634

Pizo M A, Oliveira P S (1999) Removal of seeds from vertebrate faeces by ants: effects of seed species and deposition site. Can J Zool 77: 1595-1602 
1 Poncy O, Sabatier D, Prévost M-F, Hardy I (2001) The lowland high rainforest: structure and tree species diversity. In: Bongers F, Charles-Dominique P, Forget P-M, Théry M (eds) Nouragues: dynamics and plant-animal interactions in a neotropical rainforest. Kluwer, Dordrecht, The Netherlands , pp 31-46

Pouvelle S, Feer F, Ponge J-F (2008) Topsoil as affected by dung deposition under resting places of red howler monkey (Alouatta seniculus). Pedosphere 18: 691-698

Pouvelle S, Jouard S, Feer F, Tully T, Ponge J-F (2009) The latrine effect: impact of howler monkeys on the distribution of small seeds in a tropical rain-forest soil. J Trop Ecol 25: $239-248$

Serio-SilvaJ C, Rico-Gray V (2002) Influence of microclimate at different canopy heights on the germination of Ficus urostigma seeds dispersed by Mexican howler monkeys (Alouatta palliata mexicana). Interciencia 27: 186-190

Shepherd V E, Chapman C A (1998) Dung beetles as secondary seed dispersers: impact on seed predation and germination. J Trop Ecol 14: 199-215

Simmen B, Julliot C, Bayart F, Pagès-Feuillade E (2001) Diet and population densities of the primate community in relation to fruit supplies. In: Bongers F, Charles-Dominique P, Forget P-M, Théry M (eds) Nouragues: dynamics and plant-animal interactions in a neotropical rainforest. Kluwer, Dordrecht, The Netherlands , pp 89-101

Slade E M, Mann D J, Villanueva J F, Lewis O T (2007) Experimental evidence for the effects of dung beetle functional group richness and composition on ecosystem function in a tropical forest. J Anim Ecol 76: 1094-1104

Tirado Herrera E R, Vulinec K, Knogge C, Heymann E W (2002) Sit and wait at the source of dung - an unusual strategy of dung beetles. Ecotropica 8: 87-88

Vander Wall S B, Longland W S (2004) Diplochory: are two seed dispersers better than one? Trends Ecol Evol 19: 155-161

Vulinec K (2000) Dung beetles (Coleoptera: Scarabaeidae), monkeys, and conservation in Amazonia. Florida Entomologist 83: 229-241

Vulinec K (2002) Dung beetle communities and seed dispersal in primary forest and disturbed land in Amazonia. Biotropica 34: 297-309 
1 Wenny DG (2001) Advantages of seed dispersal: a re-evaluation of directed dispersal. Evol 2 Ecol Res 3: 51-74

3

4 
3 Figure 1. Species richness, seed number and seed viability (proportion of viable seeds) in the 4 topsoil in sites frequently used (Freq+), rarely used (Freq-) by red howler monkeys (black 5 circles) and in control areas never visited by monkeys (open circles). The curve is obtained 6 with values predicted by the best model (see methods) and data points are observed values.

7 Mean values and standard error bars are presented. A small amount of noise has been added to depth data in order to visualize overlapping points.

9

10 Figure 2. Selectivity (100 - proportion of beads retrieved in dung beetle reserves in percent) 11 as a function of bead size (small, medium and large circle: S, M and L beads), dung beetle 12 functional group (open circles: tunnellers; black circles: rollers) and body size. The graph 13 shows the values predicted by the model.

14

15 Figure 3. Selectivity (100 - proportion of beads retrieved in dung beetle reserves in percent) 16 as a function of bead size (small, and medium circle: $\mathrm{S}$ and $\mathrm{M}$ beads), dung beetle functional 17 group (open circles: tunnellers; black circles: rollers) and resource per capita (dung delivered 18 per individual). 
Table 1. Monkey frequentation (Freq+, Freq- or Control) and depth effect (6 levels) on seed number, species number and seed viability. Tests were performed with GLMM models. Random effects are site and depth for seed number and species number, site for seed viability. $\sim: 0.05<\mathrm{p}<0.075, * * *: \mathrm{p}<0.001$.

\begin{tabular}{|c|c|c|}
\hline Effect & Parameter estimate $( \pm 1 \mathrm{SE})$ & Wald statistics (z) \\
\hline \multicolumn{3}{|l|}{ Species richness } \\
\hline Depth & $-0.39( \pm 0.05)$ & $-7.35 * * *$ \\
\hline Freq- $<$ Freq+ & $0.32( \pm 0.03)$ & $10.91 * * *$ \\
\hline Control<(Freq- ,Freq+ ) & $0.08( \pm 0.01)$ & $8.16^{* * *}$ \\
\hline Depth $x$ Freq- $<$ Freq + & $0.03( \pm 0.03)$ & 0.95 \\
\hline Depth x Control<(Freq- ,Freq+ ) & $0.07( \pm 0.01)$ & $6.35^{* * *}$ \\
\hline \multicolumn{3}{|l|}{ Number of seeds } \\
\hline Depth & $-0.82( \pm 0.10)$ & $-8.29 * * *$ \\
\hline Freq- $<$ Freq+ & $1.14( \pm 0.08)$ & $14.99 * * *$ \\
\hline Control<(Freq- ,Freq+ ) & $0.36( \pm 0.03)$ & $12.95 * * *$ \\
\hline Depth $x$ Freq- $<$ Freq+ & $-0.11( \pm 0.06)$ & $-1.80 \sim$ \\
\hline Depth x Control<(Freq- ,Freq+ ) & $0.07( \pm 0.02)$ & $3.34 * * *$ \\
\hline \multicolumn{3}{|l|}{ Proportion of viable seeds } \\
\hline Depth & $-0.24( \pm 0.06)$ & $-4.23 * * *$ \\
\hline Freq- $<$ Freq+ & $-0.47( \pm 0.13)$ & $-3.74 * * *$ \\
\hline Control<(Freq- ,Freq+ ) & $0.17( \pm 0.05)$ & $3.56^{* * *}$ \\
\hline
\end{tabular}


Figure 1.

FREQ +
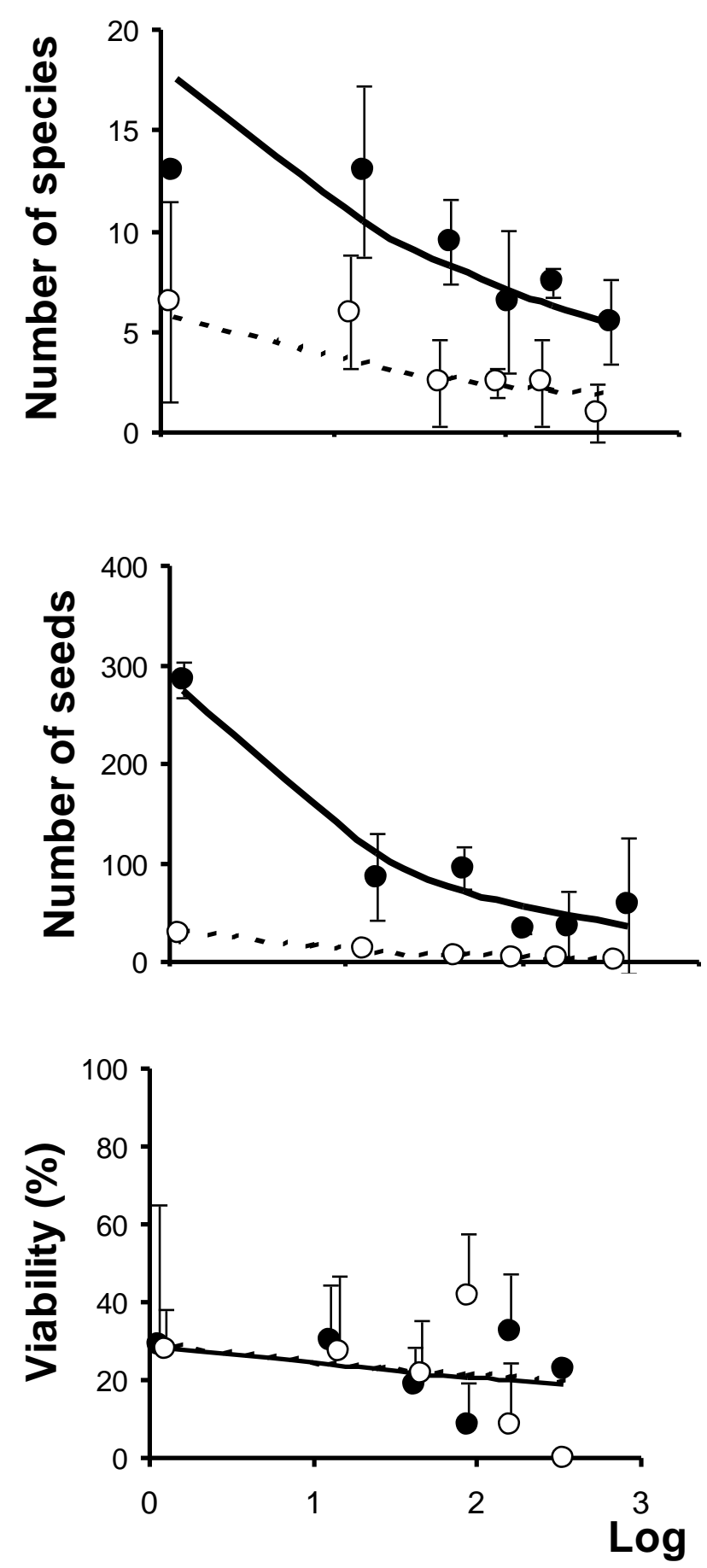

FREQ -
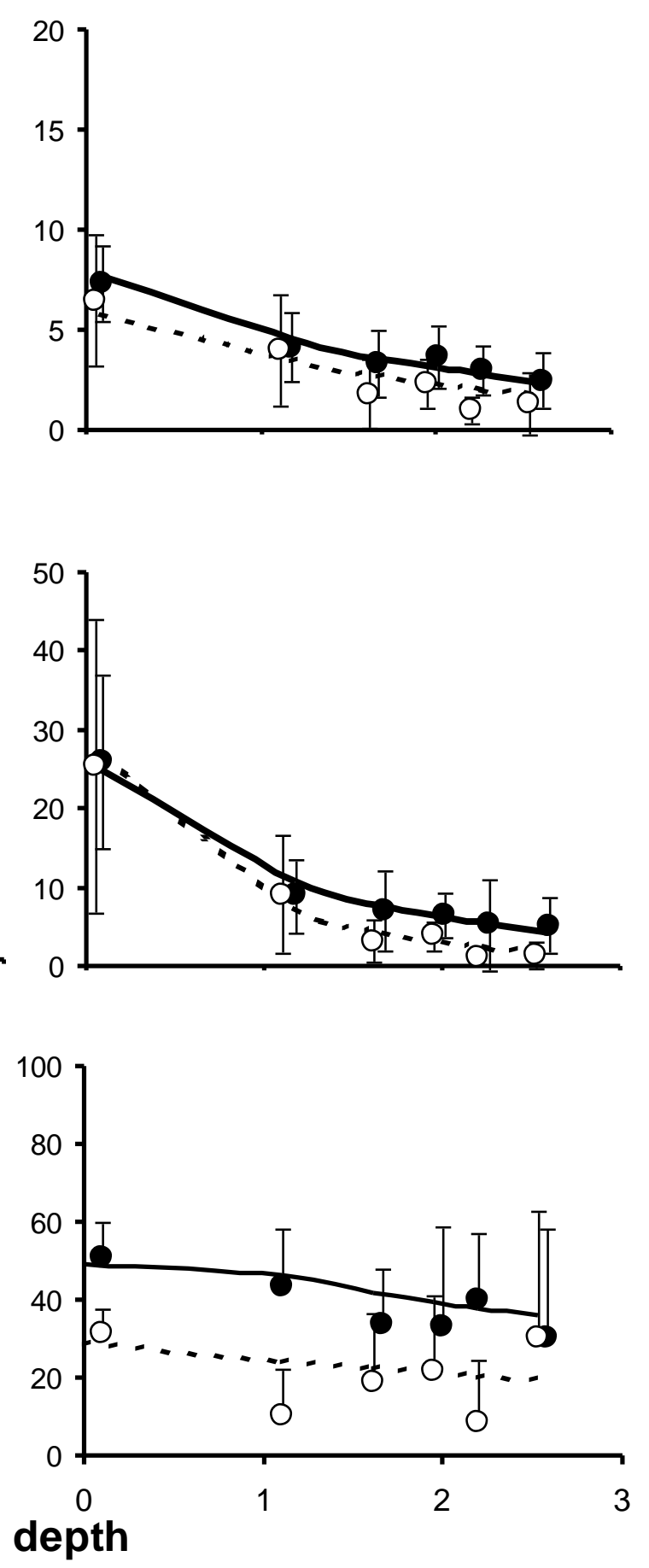
Figure 2

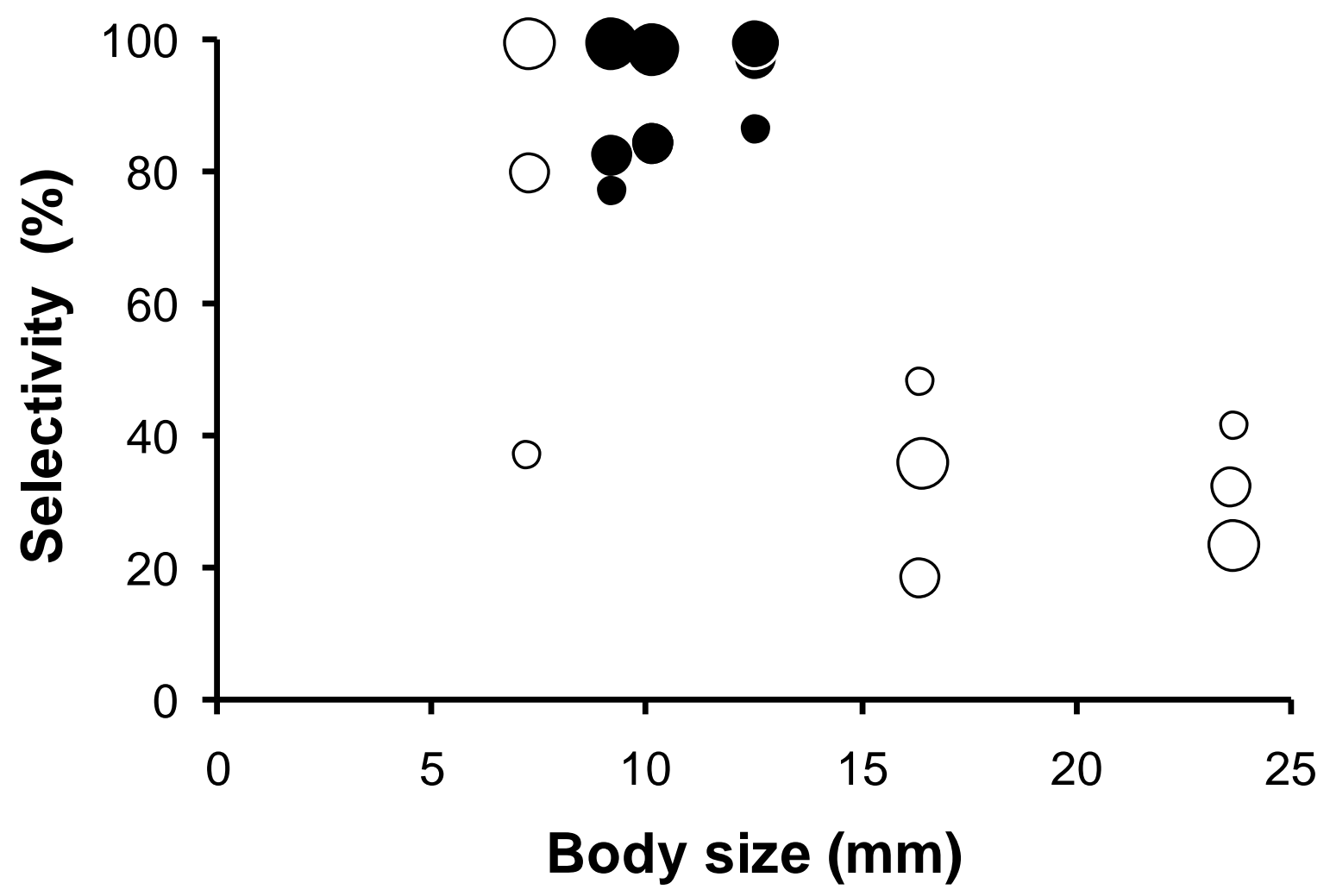


Figure 3

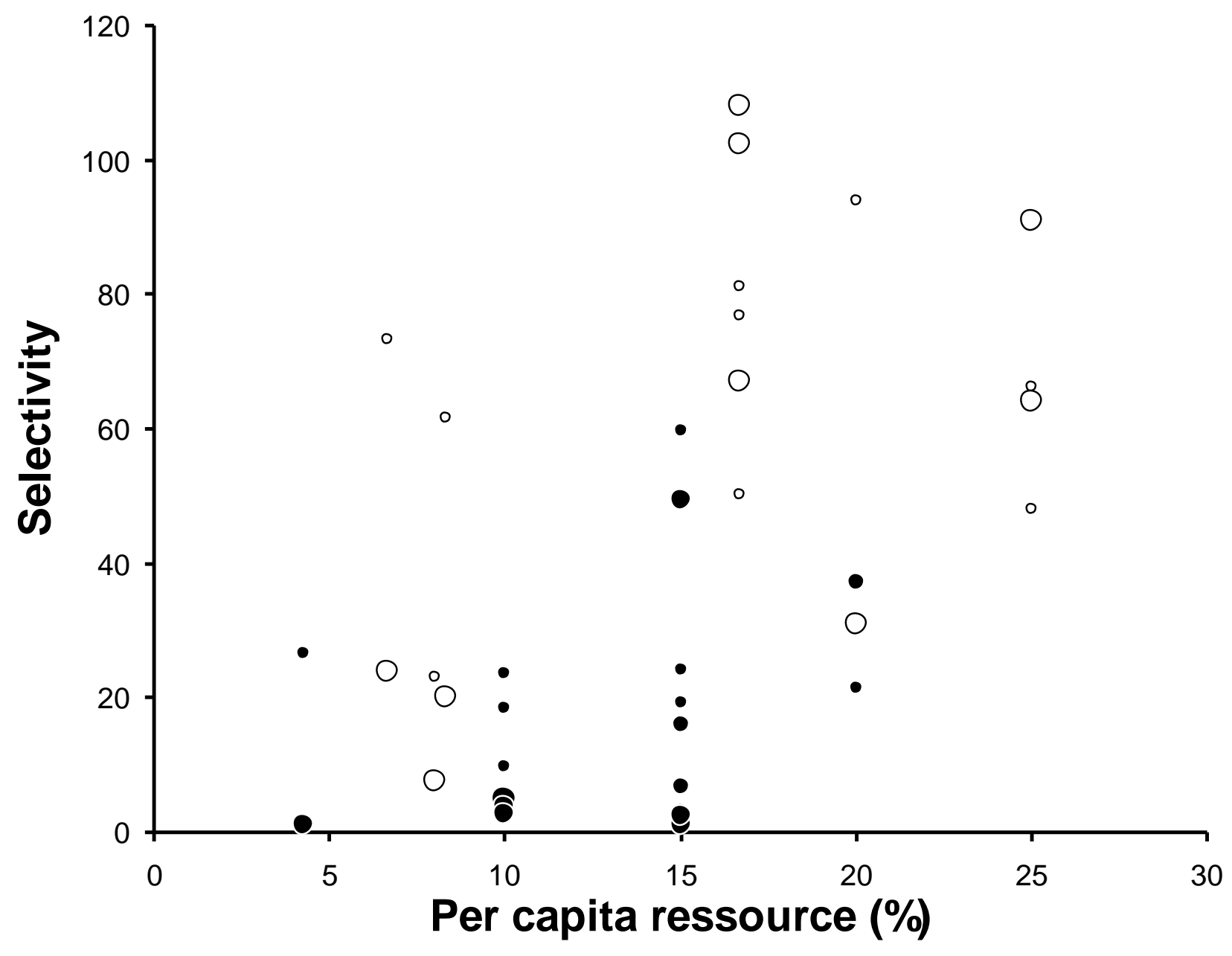

